\title{
A INTERAÇÃO ENTRE POLICIAIS MILITARES E PICHADORES NAS CIDADES DE LONDRINA E IBIPORÃ
}

\author{
Graziele Pestana (Ciências Sociais - UEL) \\ Guilherme Hiroshi (Ciências Sociais - UEL) \\ Maria Letícia dos Reis (Ciências Sociais - UEL) \\ Cleber da Silva Lopes (orientador)
}

\section{RESUMO}

A pichação é uma prática amplamente difundida nas cidades brasileiras. Se para muitos ela é apenas um comportamento juvenil desviante, para as autoridades públicas ela é um crime que deve ser reprimido nos termos do artigo 65 da Lei 9.605/98 (Lei de Crimes Ambientais), que define pena de detenção de 03 meses a 01 ano e multa para quem pichar ou por outro meio conspurcar edificações ou monumento urbano. O objetivo deste trabalho é analisar o modo como policiais militares da região de Londrina vêm a pichação e os pichadores. Qual a visão dos policiais sobre a pichação? Como eles rotulam os pichadores? Punições extrajudiciais a pichadores são admitidas? Quais medidas eles acreditam ser as mais eficazes para combater a pichação? $O$ trabalho procura responder a essas questões por meio da Análise de Conteúdo de sete entrevistas em profundidade realizadas em janeiro de 2016 com policiais militares de Londrina e Ibiporã.

Palavras-Chave: Polícia; pichadores; controle social;

\section{INTRODUÇÃO}

Não é raro andar pelo centro de qualquer cidade do Brasil e notar rabiscos ou escritos nas paredes e fachadas de prédios que muitas vezes não conseguimos compreender. Essas intervenções urbanas são conhecidas como pichações. Tal prática se encontra presente na história da humanidade desde o Império Romano (CAVALCANTI, 2013). Normalmente ela é realizada por jovens dispostos a arriscar a própria vida para deixar suas marcas em fachadas de prédios altos, pontes e locais vigiados pela polícia (SPINELLI, 2007) como forma de se auto afirmarem e se posicionarem com destaque dentro de um grupo juvenil. Mas a pichação provoca descontentamento na sociedade. Além de afetar as propriedades das vítimas, que não raramente precisam despender recursos para recuperar o local conspurcado, a pichação também fere o senso estético dos moradores das cidades, agredindo as suas concepções de limpeza e beleza. Esse descontentamento muitas vezes leva a população a apoiar e a desejar que os infratores sejam punidos por seus atos, algo que pode ter repercussão no modo como o poder público reage a essas práticas, que para todos os efeitos deve ser reprimida nos termos do artigo 65 da Lei 9.605/98 (Lei de Crimes Ambientais), que define pena de detenção de 03 meses a 01 ano e multa para quem pichar ou por outro meio conspurcar edificações ou monumento urbano.

O presente trabalho analisa a visão de agentes públicos da região de Londrina que compõem uma das principais organizações que atuam na repressão à pichação: a 


\section{SEMINÁRIO DE PESQUISA EM CIÊNCIAS HUMANAS - SEPECH \\ Humanidades, Estado e desafios didático-científicos \\ Londrina, 27 a 29 de julho de 2016}

Polícia Militar, força policial responsável pelo patrulhamento ostensivo dos espaços públicos. Qual a visão dos policiais militares sobre a pichação? Como eles rotulam os pichadores? Punições extrajudiciais a pichadores são admitidas? Quais medidas eles acreditam ser as mais eficazes para combater a pichação? $\mathrm{O}$ trabalho procura responder a essas questões por meio da Análise de Conteúdo de sete entrevistas em profundidade realizadas em janeiro de 2016 com policiais militares de Londrina e Ibiporã.

O principal referencial teórico utilizado no trabalho é a obra Outsiders, de Howard S. Becker. Este autor entende que o desvio é algo que deriva de relações existentes em determinados grupos sociais: "[d]esvio não é qualidade que reside no próprio comportamento, mas na interação entre a pessoa que comete um ato e aquelas que reagem a ele”. (BECKER, 2008, p. 27). Para Becker, nem todo desvio configura um crime, mas todo crime se caracteriza como um ato desviante. A existência de desviantes (outsiders) em sociedades complexas pressupõe a existência de empreendedores morais e de impositores de normas, isto é, pessoas que criam regras que dizem o que é certo e o que é errado e pessoas que visam impor essas normas àqueles que agem de forma errada. $\mathrm{O}$ foco deste artigo recai sobre os impositores de normas, aqui tratados como policiais militares da região de Londrina.

\section{PICHAÇÃO E REPRESSÃO: O DESVIO COMO CONSTRUÇÃO SOCIAL}

A pichação está tipificada na Lei de Crimes Ambientais (Lei 9.605/1998). De acordo com a legislação vigente em nossa sociedade, ela é considerada um crime de menor potencial ofensivo, ou seja, que não causa grande dano ou perigo à sociedade. $\mathrm{O}$ Brasil é o único país do mundo em que a legislação penal faz distinção entre grafite e pichação. Subjacente à normatização dessas duas categorias de intervenções visuais está a oposição dos conceitos de "arte" e "conspurcação". Foi também o primeiro a descriminalizar o grafite no ano de 2011. A grafia oficial da palavra é com "ch", contudo os praticantes da pichação adotam a grafia com " $x$ " sob a justificativa de se tratar de uma prática específica, ou, nos termos deles, uma "expressão artística" (CAPPELLARI; MEINHARDT). A grafia com "ch" abrange diversas formas de inscrições gráficas nas paredes, tais como casos de propagandas políticas e empresariais. Existe uma tendência em confundir grafite com pichação. Contudo, devemos ter em mente que há uma distinção entre essas duas formas de expressão. $O$ grafite tem suas origens nas artes plásticas e faz uso de imagens, enquanto a pichação tem origem na escrita e privilegia as palavras. A pichação é uma prática marginalizada, que pode ser entendida como uma forma de resistência e subversão às normas existentes na sociedade, enquanto o grafite - que em um momento anterior era também marginalizado e se enquadrava na mesma categoria da pichação - agora é aceito como uma forma de expressão artística.

... a pixação segue criminalizada e equiparada ao ato de sujar, macular, manchar, enquanto o grafite é elevado ao status de arte, desde que realizado com a autorização do proprietário e com o "objetivo de valorizar o patrimônio público ou privado mediante manifestação artística. (LARRUSCAHIM; SCHWEIZER, p 23) 


\section{SEMINÁRIO DE PESQUISA EM CIÊNCIAS HUMANAS - SEPECH \\ Humanidades, Estado e desafios didático-científicos \\ Londrina, 27 a 29 de julho de 2016}

Para o senso comum, não há estética na pichação. É um processo aleatório e anárquico no qual qualquer um pode se integrar. (CAPPELLARI; MEINHARDT p. 1). Todavia, existe um certo respeito entre grafiteiros e pichadores, uma vez que onde há grafite não há picho, e onde há picho não há grafite (DE CARVALHO, 2014). Há então um investimento na arte do grafite como estratégia para inibir a pichação.

A pichação aparece no Brasil como expressão de humor e protesto durante a ditadura militar - a prática era considerada ilegal e subversiva - e se populariza a partir dos anos 80, quando novas formas de pichação surgem, não mais apenas com caráter político e de protesto. As pichações passam a ser consideradas manifestações dos marginalizados, uma forma de produção de uma identidade desviante. A pichação é então associada com vandalismo, não mais como forma de comunicação. Diversos estudos reconhecem que a pichação deve ser entendida como uma transgressão à regra do estético, do limpo, da moral, do juridicamente correto, etc. (CAPPELLARI; MEINHARDT p. 3).

A marginalização da pichação se deve, em princípio, à sua veiculação midiática pejorativa. Desde a primeira aparição da pichação na mainstream media no fim dos anos 1980, o discurso midiático dominante tendeu a definir tal prática como sujeira, vandalismo, ou, em vários casos, até como terrorismo. Esse enquadramento do problema já trazia, implícita ou explicitamente, demandas por ações repressivas por parte dos atores políticos contra esse "inimigo público". Assim, em muitos momentos é possível observar um ativo posicionamento dos atores políticos em relação à pichação (LARRUSCAHIM; SCHWEIZER, p. 22).

Apesar de a imprensa representar os pichadores como inimigos públicos que devem ser combatidos, pouco sabemos sobre o modo como o poder público vê os pichadores, especialmente em cidades de médio porte como Londrina. Sabemos que as autoridades públicas têm a obrigação de fazer cumprir a lei e de combater a pichação. Mas também sabemos que os policiais militares são dotados de alta discricionariedade, podendo efetivamente escolher quando agir, contra quem e como. Daí a importância de conhecermos melhor o que os policiais militares pensam sobre a pichação, os pichadores e as formas de combate-los. A análise realizada na sequência, focada nas percepções dos Policiais Militares da região de Londrina, procura dar uma contribuição nessa direção.

\section{METODOLOGIA}

O estudo é baseado em uma pesquisa qualitativa com sete policiais militares das cidades de Londrina e Ibiporã desenvolvida no âmbito da Disciplina de Pesquisa e Ensino IV do Curso de Ciências Sociais da Universidade Estadual de Londrina, sob a coordenação do prof. Dr. Cleber da Silva Lopes. Os policiais foram escolhidos em um procedimento de amostragem de casos típicos (FLICK, 2009). As entrevistas foram realizadas por dois grupos de alunos matriculados na referida disciplina - Grupo Quali 2 Matutino (responsável por este artigo) e Grupo Quali 2 Noturno. O Grupo Quali 2 Matutino realizou três entrevistas com dois policiais da cidade de Ibiporã e um policial da cidade de Londrina. O contato inicial com os policiais da cidade de Ibiporã se deu a partir de uma abordagem na rua por um dos integrantes do grupo, enquanto o contato com o policial da cidade de Londrina ocorreu a partir de uma indicação. Estas 


\section{SEMINÁRIO DE PESQUISA EM CIÊNCIAS HUMANAS - SEPECH \\ Humanidades, Estado e desafios didático-científicos \\ Londrina, 27 a 29 de julho de 2016}

entrevistas foram aplicadas de maneira informal e sigilosa em uma sala reservada no Centro de Letras e Ciências Humanas da Universidade Estadual de Londrina (CLCH/UEL) e apenas uma entrevista obteve autorização para ser gravada. As demais entrevistas foram anotadas por um aluno, enquanto o outro realizava as questões. $\mathrm{O}$ Grupo Quali 2 Noturno realizou quatro entrevistas com policiais da cidade de Londrina. O contato inicial se deu a partir da visita dos integrantes do grupo ao batalhão, onde expuseram a natureza do estudo e obtiveram autorização formal para que os policiais pudessem participar. As entrevistas ocorreram na $5^{\mathrm{a}}$ Companhia Independente da Polícia Militar de Londrina e tiveram autorização para serem gravadas. Os sete policiais entrevistados possuem entre dois e dezenove anos de experiência, são predominantemente do sexo masculino (apenas um entrevistado era do sexo feminino PJ) e tiveram durante o tempo de carreira algum tipo de contato com pichadores. As entrevistas foram realizadas entre os dias 19 e 20 de janeiro de 2016; elas foram realizadas com base em um questionário semiestruturadas (BOOTH, COLOMB, WILLIAMS, 2005) composto de treze questões relacionadas ao problema de pesquisa. Realizamos a transcrição das entrevistas, a codificação e a tabulação dos depoimentos. Esses procedimentos foram realizados a partir da técnica da codificação apresentada por Gibbs (2009).

\section{RESULTADOS E DISCUSSÃO}

A análise das entrevistas mostrou que, de um modo geral, os policiais militares consideram a pichação como crime ambiental, vandalismo e depredação de patrimônio, seja ele público ou privado. Contudo, também a consideram forma de expressão quando realizada em locais autorizados. As questões contempladas na primeira parte da entrevista buscavam relacionar o aumento da pichação com o senso de impunidade. Os policiais que trabalham na cidade de Ibiporã não notaram um aumento considerável no número de pichações. A entrevista PJ, por exemplo, deu a seguinte resposta ao ser questionada se a pichação na cidade estava igual, aumentando ou diminuindo nos últimos 12 meses: "Nem muita, nem pouca né... Acho que tá mais pra pouca" (PJ). Por outro lado, os policiais que trabalham na cidade de Londrina notaram um considerável aumento dessa prática.

Com certeza nos últimos doze meses aumentou bastante. Principalmente na nossa área, na área da avenida Saul Elkind aumentou muito. Hoje pra você visualizar algum prédio na área da Saul que não esteja pichado de alguma forma é quase que impossível. Então aumentou muito, muito, muito. (PM Araújo)

No imaginário dos policiais os pichadores são geralmente jovens, estudantes do ensino médio com idade entre quatorze a vinte anos. Os policiais não consideram a condição de classe como um fator determinante para que os jovens entrem no mundo da pichação, com exceção do PM Araújo, que acredita que jovens de periferia possuem uma propensão maior a participar de tais atividades, pois sentem a necessidade de se expressar e "demarcar a sua área". 


\section{SEMINÁRIO DE PESQUISA EM CIÊNCIAS HUMANAS - SEPECH \\ Humanidades, Estado e desafios didático-científicos \\ Londrina, 27 a 29 de julho de 2016}

Eu acho que é... O principal motivo é as companhias. Acho que o meio ali de vivência e convivência da pessoa, as companhias, as companhias da escola, e o aumento também da... da... da... Do número de favelas aí na... na... na... Nossa área aí. E o ensino público gera uma convivência de pessoas aí. Eu acho que por isso que aumentou o número da pichação aí. Eu acho que um com uma mentalidade um pouco diferente, eu acho que acaba virando uma gangue, onde quer fazer esse tipo de pichação pra se destacar dos outros. (PM Araújo)

Nos relatos vemos dois tipos de respostas concernentes à pichação. A que acredita ser um ato de afronta, de crítica social, de certa inconformidade com a realidade; e a perspectiva que vê jovens sendo atraídos por más companhias e gangues. De acordo com os policiais, os fatores que motivam os jovens a ingressarem na prática da pichação são questões socioeconômicas (surgimento de favelas e convívio no ensino público), ideológicas (descontentamento com o governo, simplesmente por se tratar de um ato que vai contra as regras estabelecidas), identitárias (necessidade de ser aceito em um grupo, a própria busca por identidade, influência de amizades, hierarquia entre os próprios pichadores) e comportamentais (rebeldia, "vagabundagem", adrenalina, etc.)

Os jovens pichadores preferem, segundo os policiais, agir durante a madrugada, período de pouca movimentação de pessoas e no qual a chance de serem pegos em flagrante se reduz consideravelmente. $\mathrm{Na}$ opinião dos policiais, os pichadores dão preferência a locais altos e perigosos como fachadas de grandes edifícios, pois quanto maior o risco, mais prestígio para o autor da pichação, em conformidade com a fala de Luciano Spinelli:

Na pichação, a hierarquia é medida pelo número de aparições, na cidade, de determinada marca, é sempre importante a recorrência, e é necessário ousadia para ter o que os pichadores chamam de "IBOPE". É dado valor, sobretudo, a piches feitos em locais altos e inacessíveis, tais como pontes, topo de edifícios e locais de grande vigilância policial. (SPINELLI, 2007)

Todos os policiais entrevistados de certa forma já tiveram algum contato com pichadores, seja atendendo diretamente ocorrências de pichação, ou apenas prestando apoio. Porém, essa situação é pouco frequente, dadas as dificuldades encontradas de autuar em flagrante, ou por não haver tantas denúncias. No geral, os policiais relataram que as abordagens ocorreram de forma regular - com exceção do PM Araújo de quem falaremos adiante - seguindo todos os procedimentos legais. Os policiais abordam, detêm e encaminham os para a delegacia, local onde as devidas providencias legaisprocessuais devem são tomadas. Geralmente estes jovens são liberados em um curto espaço de tempo, segundo os policiais.

Em relação à aplicação de punições irregulares, notamos que elas não são admitidas pela maioria dos policiais. Estes adotam uma fala legalista, mas é preciso frisar que não é possível saber se essa fala é resultado de uma manifestação sincera dos policiais ou uma fala produzida em função do próprio contexto da pesquisa empírica. Ao ser questionada sobre punições irregulares aplicadas por policiais, a soldado PJ afirmou: Acho quem tem que tomar atitude quanto a isso é na justiça, é na lei, nos dois 


\section{SEMINÁRIO DE PESQUISA EM CIÊNCIAS HUMANAS - SEPECH \\ Humanidades, Estado e desafios didático-científicos \\ Londrina, 27 a 29 de julho de 2016}

casos [casos dos pichadores e dos policiais que agiram ilegalmente contra eles]". O mesmo pode ser observado na fala de Soldado:

Não é questão de concordar ou não, não é questão de foro íntimo, é uma questão legal. Se eu não concordo com a lei, devo lutar por meios legais. Eu não concordo com nenhum tipo de violência, nem por parte da população, nem por parte dos policiais. (Soldado)

Capitão Costa apresenta o mesmo posicionamento legalista ao afirmar que: " $O$ procedimento padrão é feito no caso de abordagem dentro dos ditames da lei, é preenchido um boletim de ocorrência, é encaminhado a pessoa a fazer um termo circunstanciado de infração penal". Contudo, o PM Araújo abre mão dessa ética e expõe de maneira clara e objetiva sua opinião a respeito do assunto. Quando questionado se considerava as punições regulares eficientes no combate à prática da pichação, o PM respondeu:

Nessas... nesses casos de punições regulares aí, eu acho que não... que... que não adianta nada, vamos dizer assim. Você pega ele, você encaminha pra delegacia, chega lá vai ser lavrado um tecidio (sic) onde ele vai pegar... onde ele vai pegar e assinar o nome dele lá, vai se comprometer a comparecer lá mais tarde, com o pai e a mãe se for menor, e resumindo não vai dar em nada. Acho que saindo de lá ele vai ter até mais força aí pra chegar e falar "eu fui pra delegacia e agora vou fazer pior ainda".

Quando questionado se as punições irregulares geram mais resultados no combate à pichação do que as punições regulares, o PM Araújo respondeu:

Com certeza gera mais resultados. Porque você vai pegar o cidadão ali, o indivíduo no ato da execução da pichação, onde você vai pegar o spray dele, o tipo de tinta que ele está usando e, como se diz, você vai aplicar um castigo nele ali que ele não vai esquecer jamais. Eu acho que funciona muito mais do que levar ele pra delegacia, o delegado só ouvir ele lá e ele sair lá por bem, de qualquer jeito, de qualquer forma.

Em seguida o entrevistador o questionou se ele tinha conhecimento de alguma situação envolvendo punições irregulares. O PM respondeu que sim, e assumiu já ter participado de várias situações semelhantes:

Eu já soube de vários, já participei de vários, é... A gente já... Vamos dizer assim, umas punição irregulares bem severas. Onde os pichadores que estavam, eu tenho certeza, não vão esquecer jamais assim, entendeu? Um foi obrigado a limpar o que pichou. O outro foi obrigado a pichar a mão, a cara, o rosto, a face, o corpo, pra ele não esquecer jamais que aquilo que ele está fazendo ali é um ato de vandalismo que não deve ser feito de forma alguma.

Diante de tal relato é importante ressaltar que o apoio às punições irregulares é aceito por uma minoria: apenas um dos sete policiais confirmou ser a favor de práticas 


\section{SEMINÁRIO DE PESQUISA EM CIÊNCIAS HUMANAS - SEPECH \\ Humanidades, Estado e desafios didático-científicos \\ Londrina, 27 a 29 de julho de 2016}

que violam os princípios de direitos humanos. Diante disso, consideramos importante propor a seguinte questão: seria o posicionamento legalista assumido pelos policiais militares de fato verdadeiro, ou as circunstâncias em que as entrevistas foram realizadas (formal, informal, gravadas, não gravadas) teriam de alguma forma interferido em suas respostas? O fato de apenas um policial ter admitido o uso de punições irregulares contra pichadores parece destoar dos resultados da pesquisa "Direitos Humanos e Cultura Policial na Polícia Militar do Estado do Paraná" (LOPES, RIBEIRO E TORDORO, 2016). Essa pesquisa descobriu que os policiais em geral rejeitam os direitos humanos, principalmente os policiais mais jovens.

Os resultados expostos anteriormente confirmam a hipótese de que os policiais militares do Paraná têm visão predominantemente desfavoráveis aos direitos humanos. (...) é entre os policiais mais jovens e supostamente menos socializados na cultura policial que encontramos as maiores resistências aos direitos humanos. (LOPES, C.S; RIBEIRO, E. A.; TORDORO, M. p. 19-21. No Prelo)

Desse modo, acreditamos ser necessário um estudo mais aprofundado e elaborado sobre esta questão das punições irregulares, haja vista que o número de entrevistados pode ter sido insuficiente para apreender com veracidade esse aspecto.

Ainda dentro do contexto das punições ilegais, quando questionados qual atitude tomariam no caso de presenciar colegas de trabalho praticando tais punições, percebemos que a questão da cultura policial tem um peso considerável nas respostas dos policiais. Quatro dos sete policiais afirmaram não informar o fato, preservando o colega de trabalho e respeitando a hierarquia policial. Reiner (2007) define esse comportamento como característico da cultura policial, na qual se encontram presentes o isolamento e solidariedade entre os policiais. O isolamento é resultado dos turnos de trabalho, da falta de horários, da dificuldade de se desligar das tensões geradas pelo serviço, e da hostilidade que os policiais enfrentam dos cidadãos comuns. A solidariedade interna entre os policiais é fruto não apenas do isolamento a que se submetem na profissão, mas também da necessidade de confiar no colega de trabalho em situações de risco, "uma armadura protegendo a força como um todo para que o público não conheça suas infrações” (p. 140-141). Diante disso, é possível compreender os motivos que levam os policiais a se negarem a denunciar seus colegas de trabalho, este fato se deve tanto à questão da solidariedade interna, quanto ao respeito à hierarquia presente na organização militar.

[...] nós não podemos... se a gente tem um problema ali que o problema da pichação, a gente não pode criar um outro problema, que seria o problema pro policial, de estar teoricamente abusando da sua autoridade ou de estar cometendo algum tipo de agressão. Então a primeira coisa que a faz é manter aquele primeiro problema que a gente não pode resolver no primeiro momento e evitar o segundo problema, evitar o segundo o problema e tentar acalmar a situação, a gente entende que isso pode ser que aconteça, a gente tenta acalmar a situação [...] (PM Babugia)

[...] o sistema militar é rígido, tudo depende do mais graduado ou não, se for alguém mais "moderno" você pode reprender no ato, moderno é 


\section{SEMINÁRIO DE PESQUISA EM CIÊNCIAS HUMANAS - SEPECH \\ Humanidades, Estado e desafios didático-científicos \\ Londrina, 27 a 29 de julho de 2016}

como agente chama os policias mais novos, mas se é alguém de um cargo mais alto, o que dá para fazer é depois chegar nele falar no canto para deixar "de boa que não é assim. (Sr. X)

Quanto aos três policiais que denunciariam seus colegas, o fariam por seguirem estritamente o que é estabelecido pela lei: "Voz de prisão! Pois ele [...o colega...] estaria cometendo prevaricação, deixando de cumprir o que a lei manda" (Soldado). Ao responder esta questão, o entrevistador questionou se ele daria voz de prisão mesmo sendo um policial acima dele na hierarquia. $\mathrm{O}$ entrevistado respondeu que sim. Nota-se nessa fala uma forte inclinação de respeito às regras legais, que consideram estar acima de qualquer contexto ou situação.

Reiner (2007) afirma que “' 'a personalidade do trabalho' não é um fenômeno psicológico individual [...], mas uma cultura socialmente gerada. É a resposta a uma combinação única de facetas do papel da polícia” ( p. 135). Skolnick (1966, p 44 apud Reiner, 2007) destaca duas dessas facetas, isto é, "duas variáveis principais, o perigo e a autoridade que devem ser interpretadas à luz de uma pressão 'constante' de parecer eficientes". Logo, a solidariedade em relação à transgressão dos pares e o respeito à hierarquia presentes no discurso dos entrevistados, mencionados anteriormente, podem ser encarados como fenômenos decorrentes da cultura policial.

A questão da impunidade no discurso dos policiais militares, aponta para a ineficácia da lei em relação aos crimes de pichação; para os transtornos causados aos donos dos estabelecimentos ou residências conspurcadas e ao Estado, que muitas vezes tem de arcar com os custos das reparações. Segundo o relato dos policiais entrevistados este fato engendra na população um sentimento de impunidade, levando a um respaldo das punições irregulares aplicadas tanto pelos policiais, quanto pela própria sociedade. Sr. X acredita que "(...) o senso de impunidade que acaba gerando essa situação, é todo um sistema que cria a violência (...)”. PJ considera que além do fato da penalidade aplicada aos infratores ser insuficiente, muitas vezes os praticantes da pichação são adolescentes, o que diminui ainda mais as chances de serem punidos. A respeito disso, ela diz:

(...) geralmente é adolescentes, no caso não vai ter essa penalidade aí, de três meses a um ano de detenção, por ser menor de idade, aí isso tudo complica bastante. Geralmente a gente tem muitos adolescentes que cometem esse crime.

Tenente Kenzo ao ser questionado sobre a tendência da população a apoiar punições irregulares, considera que: “(...) a sociedade está cansada de impunidade. Então pelo menos com uma punição irregular, ele sabe que ele não vai estar ileso da situação".

Outra analise que se pode fazer a partir das informações extraídas das entrevistas se refere às possibilidades de se conseguir um resultado satisfatório no combate à essa situação. Os policiais acreditam que a prática da pichação deve ser combatida através de medidas educativas, no período escolar, mas também em seu contraturno. Concordam que há a necessidade de locais destinados a tal prática e que poderiam, inclusive, realizar a reforma de locais abandonados. Se faz necessário também, de acordo com os policiais, que os pichadores ressarçam os proprietários prejudicados com suas práticas. Entendem que tanto os jovens quanto seus pais devem arcar com esse prejuízo 


\section{SEMINÁRIO DE PESQUISA EM CIÊNCIAS HUMANAS - SEPECH \\ Humanidades, Estado e desafios didático-científicos \\ Londrina, 27 a 29 de julho de 2016}

financeiro. Deve haver um projeto de educação para mudar a mentalidade desses jovens. Há também a sugestão de agencias policiais especializadas no combate à pichação, que contaria com banco de dados contendo fotografias e relação de boletins de ocorrência para facilitar a identificação dos pichadores.

\section{CONSIDERAÇÕES FINAIS}

Concluímos a partir dessa análise que existem certas limitações para se compreender a totalidade da relação dos policiais militares com os pichadores. Contudo, essas possíveis limitações não nos impedem de captar algumas parcelas relevantes dessa realidade. A pichação é vista de maneira unânime pelos policiais entrevistados como um ato desviante e os pichadores são rotulados como jovens vândalos que desrespeitam regras. Podemos levantar a hipótese de que denúncias de crimes de pichação são menos recorrentes do que outros crimes, tal como denúncias de tráfico de drogas. Percebemos isso na fala do policial Sr. X, que quando questionado a respeito do perfil social dos pichadores respondeu: "Com 4 anos na polícia eu não tenho esse conhecimento. Com trafico geralmente a gente sabe". Teríamos que realizar uma pesquisa mais aprofundada para apreendermos com fidedignidade essa questão.

\section{REFERÊNCIAS BIBLIOGRÁFICAS}

BECKER, H. Outsiders: estudos de sociologia do desvio. $1^{\text {a }}$ ed. Rio de Janeiro: Zahar, 2008

BOOTH, W.; COLOMB, G; e WILLIAMS, J. "De tópicos a perguntas", "De perguntas a problemas" e "De perguntas a fontes de informações" e "Sugestões úteis: leitura rápida". In ibid. A Arte da Pesquisa. São Paulo: Martins Fontes, 2005 (pp. 45-58; 63-83 e 85-96; 108-111).

CAPPELLARI, A.; MEINHARDT, Y. Pixações em Santa Cruz do Sul: Discursos em Spray. SBECE/SIECE, 6., 2015, Santa Cruz do Sul. Anais eletrônicos. Disponível em: $<$ http://www.sbece.com.br/resources/anais/3/1430086656_ARQUIVO_Artigo-sbecefinal $\% 281 \% 29$.pdf $>$ Acesso em: 02/11/2015.

CAVALCANTI, Daniel Sousa de Holanda. O que é grafite e pichação?. Limiares da História. Disponível em: <http://limiaresdahistoria.blogspot.com/2009/08/arte-de-ruagrafite-e-pichacao.html>. Acesso em: 25/02/2016

FLICK, U. "Amostragem, seleção e acesso". In ibid. Desenho da Pesquisa Qualitativa. Porto Alegre: Artmed, 2009 (pp. 43-55)

LARRUSCAHIM, P. G.; SCHWEIZER, Paul. A Criminalização da Pixação Como Cultura Popolar na Metrópole Brasileira na Virada para o Século XXI. Revista de Direitos e Garantias Fundamentais - Edição Temática "Criminologia Crítica em Debate". Vitória - ES, v. 15, n. , p. 13 - 32. 2015. Disponível em: < 


\section{SEMINÁRIO DE PESQUISA EM CIÊNCIAS HUMANAS - SEPECH \\ Humanidades, Estado e desafios didático-científicos \\ Londrina, 27 a 29 de julho de 2016}

http://www.fdv.br/sisbib/index.php/direitosegarantias/article/view/650/200> Acesso em: $02 / 11 / 2015$.

LOPES, C.S; RIBEIRO, E. A.; TORDORO, M. "Direitos Humanos e Cultura Policial na Polícia Militar do Estado do Paraná". Sociologias. No prelo

NETO, P. M. Violência Policial no Brasil: Abordagens Teóricas e Práticas de Controle. In: DULCE CHAVES PANDOLFI; JOSÉ MURILO DE CARVALHO; LEANDRO PIQUET CARNEIRO; MARIO GRYNSZPAN. (Org.). Cidadania, Justiça e Violência. Rio de Janeiro: Fundação Getúlio Vargas, 1999. p. 129 - 148.

REINER, R. A Cultura Policial. In: ROBERT REINER. A Política da Polícia. São Paulo: Edusp, 2007. p. 131-160.

RODRIGUES, José Eduardo Ramos. Aspectos criminais da pichação. MPMG Jurídico, Belo Horizonte, edição especial, p.60-64, 2013.

SPINELLI, Luciano. Pichação e comunicação: um código sem regra. Logos, v. 14, n. 1, p. 111-121, 2007. 